\title{
Critical kick-back mitigation through improved design of demand response
}

\author{
Han, Xue; You, Shi; Bindner, Henrik W.
}

Published in:

Applied Thermal Engineering

Link to article, DOI:

10.1016/j.applthermaleng.2016.09.053

Publication date:

2016

Document Version

Peer reviewed version

Link back to DTU Orbit

Citation (APA):

Han, X., You, S., \& Bindner, H. W. (2016). Critical kick-back mitigation through improved design of demand response. Applied Thermal Engineering, 144, 1507-1514. https://doi.org/10.1016/j.applthermaleng.2016.09.053

\section{General rights}

Copyright and moral rights for the publications made accessible in the public portal are retained by the authors and/or other copyright owners and it is a condition of accessing publications that users recognise and abide by the legal requirements associated with these rights.

- Users may download and print one copy of any publication from the public portal for the purpose of private study or research.

- You may not further distribute the material or use it for any profit-making activity or commercial gain

- You may freely distribute the URL identifying the publication in the public portal

If you believe that this document breaches copyright please contact us providing details, and we will remove access to the work immediately and investigate your claim 
Research Paper

\title{
Critical kick-back mitigation through improved design of demand response
}

\author{
Xue Han, Shi You*, Henrik Bindner \\ Center for Electric Power and Energy, Technical University of Denmark (DTU), Denmark
}

\section{H I G H L I G H T S}

- A detailed explanation of load kick-back caused by demand concurrency.

- A comprehensive investigation of three kick-back mitigation algorithms.

- A heat pumps-based DSR fleet is simulated to support a comparative analysis.

- Detailed understanding of DSR's flexibility (or saturation conditions) is a must

\section{A R T I C L E I N F O}

\section{Article history:}

Received 15 April 2016

Revised 2 September 2016

Accepted 10 September 2016

Available online $\mathrm{xxxx}$

\section{Keywords:}

Demand response

Kick-back effect

Demand side resource

Coordinated control

\begin{abstract}
A B S T R A C T
The energy sector is adopting a lot of intermittent renewable energy sources nowadays. In order to successfully integrate these renewable sources, demand side resources (DSR), in a demand response (DR) setup, are able to provide power system services by exploiting their flexibility in power consumption. Load kick-back effect describes a dynamic process that the total power consumption of a population of DSRs is higher than the expected value during the steady state after the activation of DR program, due to their temporary synchronous behaviors. For DR programs designed with little consideration of load kick-back, not only the potential value of DR is limited significant but also power system operation can be jeopardized even more. In addition to explaining the severity of kick-back effect through illustrative examples, this paper proposes several methods to mitigate the critical kick-back effect in DR while maintaining the expected value of DR. The proposed methods are applied to a DR program that aims at using thermostatically controlled heating of residential houses for peak shaving. Quality measures are adopted to measure the performance.
\end{abstract}

๑) 2016 Elsevier Ltd. All rights reserved.

\section{Introduction}

Aimed at a more sustainable energy system, there is rapid growth of clean energy solutions connected to the existing power system infrastructure. At the supply side, the amount of intermittent renewable has been increased by almost 10 times in the last decade [1], if taking wind power as an example. At the end-user side, demand side resources (DSR), such as small wind turbines (WT), rooftop photovoltaic panels (PV), electric vehicles (EV), and heat pumps (HP) are also getting more and more recognizable [2]. Power system operation is significantly challenged by both

\footnotetext{
The work is supported by Danish national project iPower - a Strategic Platform for Innovation and Research within Intelligent Electricity (SPIR), and a Sino-Danish Renewable Energy Development (RED) Project.

* Corresponding author.

E-mail addresses: xueh@elektro.dtu.dk (X. Han), sy@elektro.dtu.dk (S. You), hwbi@elektro.dtu.dk (H. Bindner).
}

trending developments with intermittent generation profiles and increased peak energy consumption respectively.

Demand response (DR) plays an essential role in integrating of renewable sources and DSRs. An import function achieved by DR is to mobilize the flexibility of controllable DSRs to actively participate in providing power system services. With supporting control and communication infrastructure, DSRs are capable to shift their energy production or consumption, such that they can be treated as intermediate energy storage with certain operating constraints [3-5]. Flexibility is referred to the flexible portion of their energy generation or consumption constrained by the primary applications and technical limitations. DR program is proposed for balancing the energy supply and demand [6,7] and solving the congestion problems [8-10] with various types of DSR technologies and control strategies. This paper is focused on realizing unscheduled DR services with real-time control strategies.

Load kick-back effect, a.k.a., "rebound effect”, "pay-back effect" or "cold load pick-up" is originally referred to as the phenomena 
that load may exceed the level during the steady state before the outage during the system restoration [11]. Recently, it is also observed in some DR programs after the flexibility from DSRs is activated [12-14]. Load kick-back effect in DR programs will lead to bad quality of service delivery and failure in complying the contract. It may even create larger congestion problems in the power system. Therefore, it is important that such issue is taken good care of in a DR program to obtain its maximal value. A rebound peak in kick-back effect is because of all DSR units behave synchronously forced by the external control signal provided by the DR program and by their operating constraints. In [12], the EV fleet is instructed to charge when price is low. The new charging schedule introduces several peaks in a day. The author in [13] coordinates the consumption of water heaters to reduce the peak load. Although the original peak in the peak hours is reduced by switching off the water heaters, a new peak is created when the water heaters are reconnected to the network. Even worse case is found in [14]. By controlling the cooling setpoint of thermostatically controlled load in commercial buildings, DR program is able to reduce the heating and cooling load during the original peak hours, but kick-back load is even larger than the original peak value (green and purple curves in Fig. 1). Among various design of DR programs, kick-back effects happen mostly during the situation when an identical control signal (either in a form of control setpoints, incentive signals, or predefined control trajectories) is received by a population of DSRs and they react to the control signal in the same way.

To mitigate the critical kick-back peaks, the author in [14] tries to reduce the new peak by extending the curtailing period. However, specific technical constraints of thermostatic loads, such as room temperature bounds, are not well considered. A model of flexibility product is defined in [7], which characterizes the kickback effect as a rebound curve. However, it is not explained in the article how this characteristic curve can be kept in a DR program. In other cases, such as $[15,16]$, the loads are scheduled in advance to achieve the control goal. However, such control strategies strongly reply on the prediction of external inputs, and the prediction errors and unforeseen disturbances may lead to unsatisfactory results during the operation. In addition, unscheduled system service may also need DSRs to provide their flexibility. Therefore, this paper focuses on proposing a few methods on how a DR program coordinates DSRs in real-time to reach the control objective, in the meanwhile takes care of the kick-back effects. The methods described here are suitable for facilitating the flexibility product agreed between the power system service vendor, i.e. aggregator, and the DSRs of its flexibility portfolio.

The contribution of this work is two folded. Firstly, the dynamic process of load kick-back effect is illustrated to help readers under-

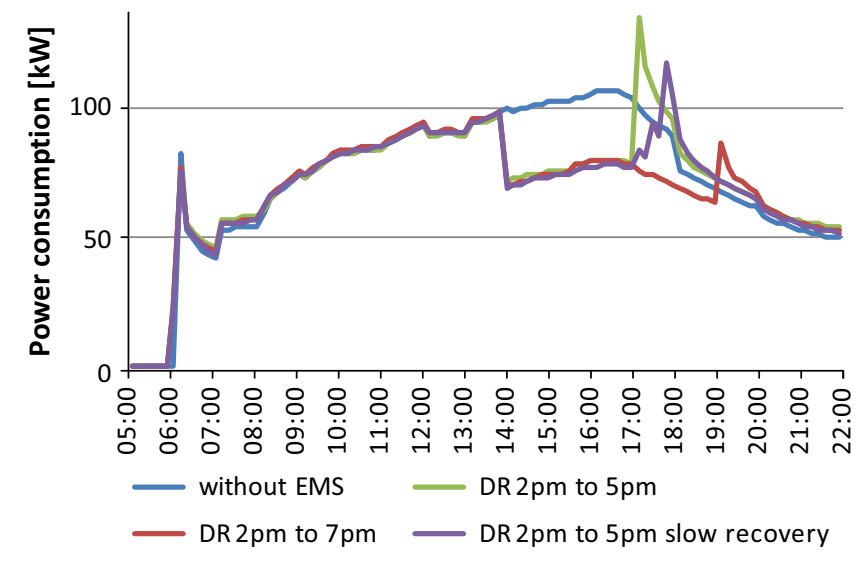

Fig. 1. Simulated HVAC peak load in a commercial building with and without DR during a summer day. Adapted from [14]. stand how the kick-back peak is created among a population. An aggregation framework is used for enabling the DR program. The power system impact is also presented showing the severity of kick-back effect concerning the system safety and operational efficiency. Secondly, a few methods are proposed to mitigate critical load kick-back effect. The control performance is evaluated against performance measures. To achieve the goals, a model of air-source heat pump system is provided, and a DR service, peak shaving service is formulated in the paper. However, the methods can always be generalized for different kinds of DSR technologies and different DR services.

The reminder of the paper is structure as follows. Section 2 presents the models, aggregation framework, and the control setup in this work. In addition, an illustrative example of kick-back is described to explain the phenomenon. It is followed by Section 3 with a few solutions to kick-back mitigation. Simulation results are presented to show the performance. Section 4 take the simulation results and evaluate the performance of individual control solutions with performance metrics. The work is concluded in Section 5.

\section{Kick-back effect}

A population of homogeneous DSRs is coordinated by an aggregator to perform demand response, which is an interface between the power system operator and individual DSR units. The aggregation framework is presented in Fig. 2. The aggregator aggregates the flexibility from DSRs into a larger scale and responds to the requests from power system operator on mobilizing the flexibility. It is responsible for delivering the power system services in an agreed service quality, and communicates with all DSR units at their owners' premises. The DSR units can either be directly controlled by the aggregator, or react to an incentive signal derived from the system operating condition [5]. In this paper, both approaches are considered to enable DR programs. Residential houses heated by thermostatically controlled heat pumps are served as DSRs to be controlled in this work.

The DSR models and the detailed implementation of the aggregation setup between the aggregator and DSRs are elaborated in this section. In addition, the load kick-back effect and its impact on power system operation are illustrated.

\subsection{Dynamic process}

The black curve in Fig. 4 shows an aggregated dynamic behavior of a fleet of 70,000 thermostatically controlled heat pumps, which are used for heating up the residential buildings. The aggregated power profile is simulated using a bottom-up approach. The behaviors of individual heat pumps are characterized in the simulation, so as the associated residential houses. The thermal usage of a house are characterized by a first order dynamic model (see the Eq. (1)). The value of the indoor temperature $T_{\text {in }}\left[{ }^{\circ} \mathrm{C}\right]$ represents the amount of energy stored in the house. It is affected by the out-

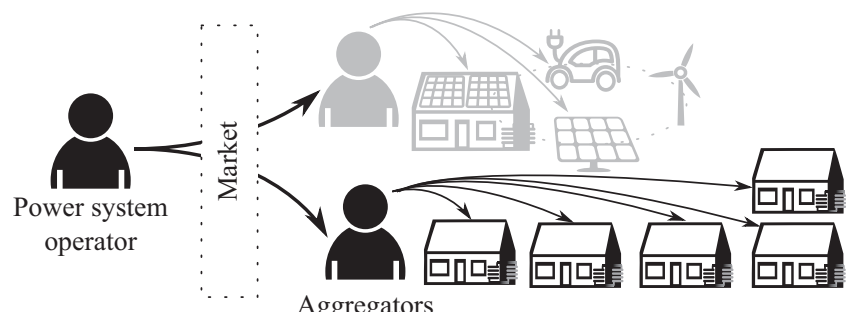

Fig. 2. A simple diagram of the aggregation framework. 
door temperature $T_{\text {out }}\left[{ }^{\circ} \mathrm{C}\right]$ due to the house's insulation, and the heating energy input from the heat pump system Heat $_{\mathrm{HP}}[\mathrm{kW}]$ that compensates the thermal loss. The discretized expression of the model using tas the time sample of building $j$ is expressed as

$T_{\text {in }, j}(t+1)=A_{j} T_{\text {in }, j}(t)+B_{0, j} H_{e a t} t_{\mathrm{HP}, j} \Delta t+B_{1, j} T_{\text {out }, j}+\eta_{j}(t)$,

where $\Delta t$ is the sampling period. $A_{j}, B_{0, j}$, and $B_{1, j}$ are parameters of the discrete thermostatic model. $\eta_{j}$ is a disturbance input caused by e.g., opening and closing the window. This discretized form is derived from a validated first order thermal model (presented in (2)) of Power FlexHouse, a real house faciliated in SYSLAB [17], Risø, Denmark. Ambient temperature as an external input is illustrated in Fig. 3, which is also measured at Power Flexhouse during winter time.

$C_{j} \frac{d T_{\text {in }, j}(t)}{d t}=-\frac{1}{R} T_{\text {in }, j}(t)+$ heat $_{j}(t)+\frac{1}{R} T_{\text {out }, j}(t)+\eta_{j}(t)$,

where the parameters $C_{j}$ and $R$ are respectively the lumped thermal capacity of the building and the thermal resistance of the building towards the exterior environment. The value of $C_{j}$ depends on the size of the building. The relation between $\left(A_{j}, B_{0, j}, B_{1, j}\right)$ and $\left(C_{j}, R\right)$ is expressed as follows.

$$
\begin{aligned}
& A_{j}=1-\frac{\Delta t}{C_{j} R}, \\
& B_{0, j}=\frac{\Delta t}{C_{j}}, \\
& B 1=\frac{\Delta t}{C_{j} R} .
\end{aligned}
$$

The statistical distribution of associated parameters are summarized in Table 1, which are obtained from the analysis of the data provided by the Danish National Register of Buildings (BBR) [18]. The detailed modeling approach can be found in [19].

The heat pump circulates a refrigerant and transmits the energy from one volume to another in a closed loop. The coefficient of performance (COP) indicates how efficiently the heat pump uses electric power to heat the house, and is set to a constant value 3.4 [20] to simplify the model. The size of a heat pump is depending on the required thermal power of its associated house. Each building is equipped with a thermostat which controls the indoor temperature according to a range $\left[T_{\mathrm{in}}^{\mathrm{min}}, T_{\mathrm{in}}^{\mathrm{max}}\right]$ around a set-point $T_{\text {ref }}\left[{ }^{\circ} \mathrm{C}\right]$. The thermostatic control algorithm is defined as

$$
\text { Heat }_{\mathrm{HP}, j}=P_{\mathrm{HP}, j} \cdot \mathrm{COP} \cdot \Delta t, P_{\mathrm{HP}, \mathrm{j}, t}=P_{\mathrm{HP}}^{\mathrm{rate}} \cdot o_{\text {state }, t},
$$

where $P_{\mathrm{HP}}^{\mathrm{rate}}[\mathrm{kW}]$ is the rated electric power of the HP, Heat $t_{\mathrm{HP}, j}[\mathrm{kWh}]$ is the heat energy generated by the HP within the sampling period, $P_{\mathrm{HP}, j}[\mathrm{~kW}]$ is the electric power consumption of the HP at time $t$, and $o_{\text {state } t}$ is the binary thermostatic operating state, determined by the

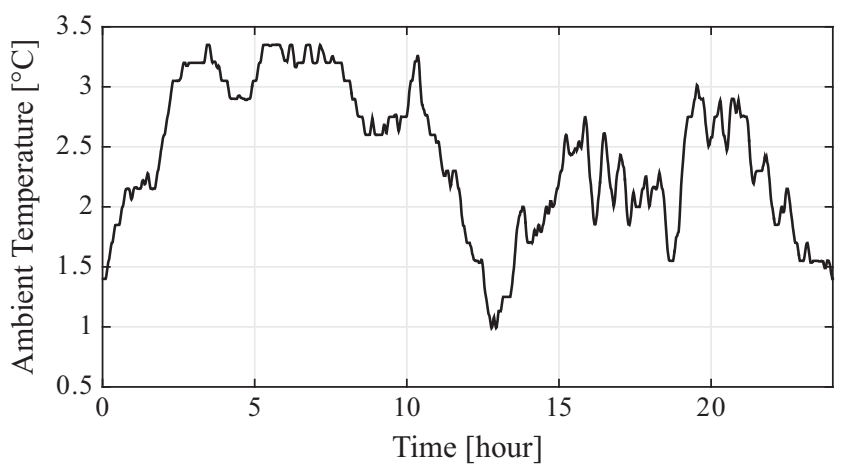

Fig. 3. The ambient temperature used for simulations.
Table 1

Statistical distribution of house parameters.

\begin{tabular}{cc}
\hline Parameter & Distribution \\
\hline$C_{j}$ & $\Gamma(22,63)$ \\
$R$ & $5.3+\mathscr{N}\left(0,0.5^{2}\right)$ \\
\hline
\end{tabular}

current indoor temperature and the demand response setpoint $O_{\text {grid }, j, t}$ :

$o_{\text {state }}(t)= \begin{cases}0 & T_{\text {in } j} \geqslant T_{\text {in }}^{\max } \\ 1 & T_{\text {in }, j} \leqslant T_{\text {in }}^{\min } \\ o_{\text {state }}(t-1) * o_{\text {grid }, j} & \text { otherwise. }\end{cases}$

In our setup, HPs can only be turned off when they are on, but cannot be forced on when they are off. The impulse responses of this DSR fleet are illustrated in Fig. 4, in which all the HPs are asked to stop consuming power for $2 \mathrm{~h}$ (black curve) and $10 \mathrm{~h}$ (gray curve). During this dynamic process, the state of individual HPs are observed. The mark " $\bigcirc$ " indicates a steady state of the aggregated power consumption before the event being triggered. Then the consumption of HPs starts to be curtailed. The distribution of indoor temperature is similar to that in the previous stage, while the states of all HPs are off. The mark " $x$ " indicates when the curtailment is finished. Most of the HPs are turned on to resume the indoor temperature after a while ("•"), of which the time length is depending on the time constant of the house. At the moment when is marked by "+", the total power consumption is close to that in steady state, however the distribution of indoor temperature is not resumed. Therefore, the total power consumption continue to oscillate. The snapshots of distribution of indoor temperatures and on/off states at the marked time instants are presented in Fig. 5. More detailed explanation of different stages is described in our previous work [19].

To understand the impact of the controlling period, $10 \mathrm{~h}$ curtailment is examined as the gray curve in Fig. 4. Evidently, the peak after stopping DSRs from consuming for $2 \mathrm{~h}$ is smaller than the peak generated after stopping DSRs from consuming for $10 \mathrm{~h}$. After $10 \mathrm{~h}$ termination, the fleet consumption is almost equal to the value during the steady state of pre-activation. The flexibility of the population is exhausted. The frequencies of the oscillations of these two cases are very close. This fact indicates that the dynamic feature of the population is depending on the time constant of the house thermal models and the distribution of the parameters of this population.

\subsection{Control formulation in a DR program}

The flow chart in Fig. 6 illustrates the control structure of the setup in this work. An aggregator delivers the service with a certain quality agreed with the power system operator. Specific service requirement is provided as an input to the aggregator controller. For DR programs designed with little consideration of load kickback, an aggregator sends out control signals every 10 min during the service activation period to all its contracted DSR units and expects desired aggregated performance. However, kick-back load may limit the potential value of DR if it is not taken good care off. As the total energy stored in buildings should resume to steady state, the energy curtailed during the activation period is shifted and relocated to post-activation period. Therefore, during the activation period, the service should allow some space to locate kickback load.

In the design of critical kick-back mitigation, the aggregator adjusts the control signals depending on the difference between the aggregated performance of the DSR fleet and the required total 


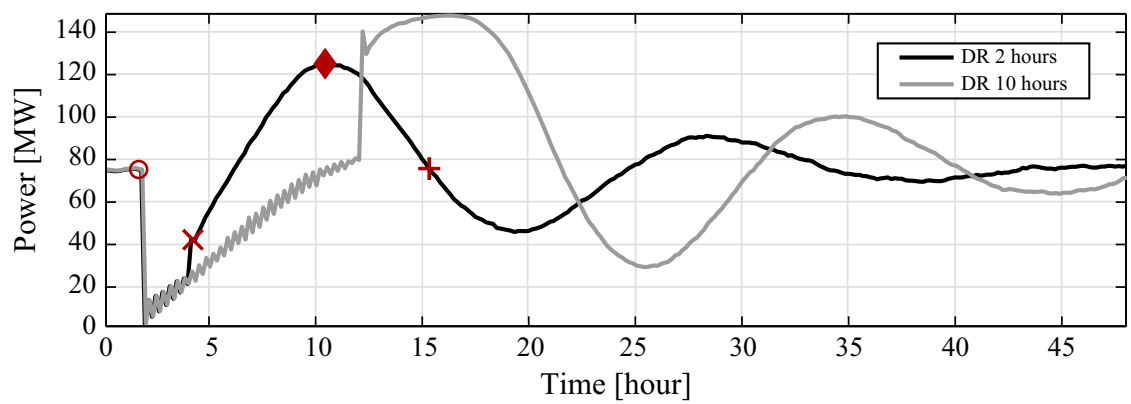

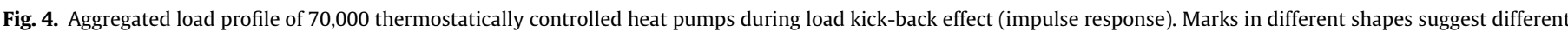
stages of the dynamic process.
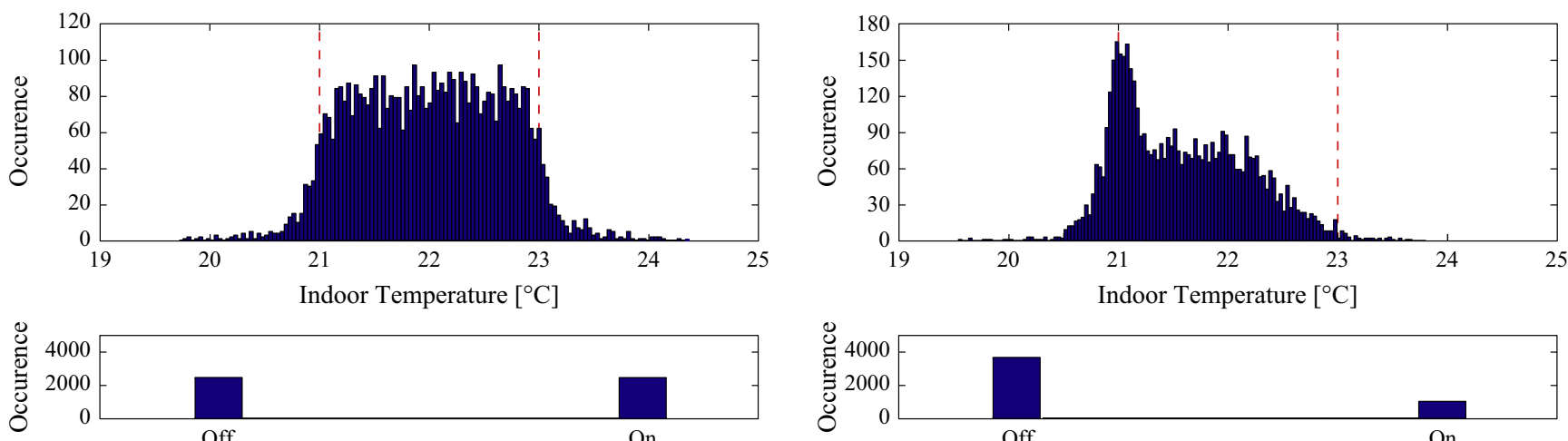

On/Off State

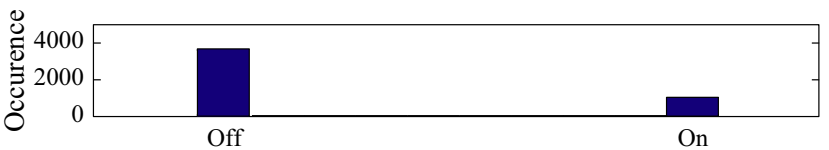

On/Off State

(a) Stage "o"

(b) Stage " $x$ "
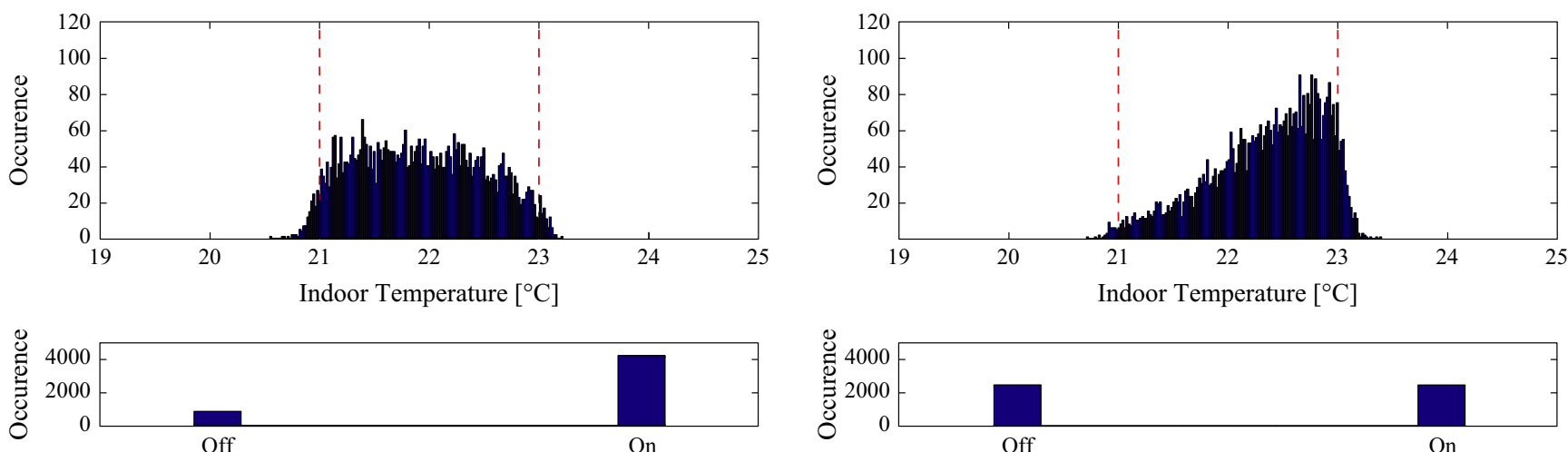

On/Off State

(c) Stage " $"$

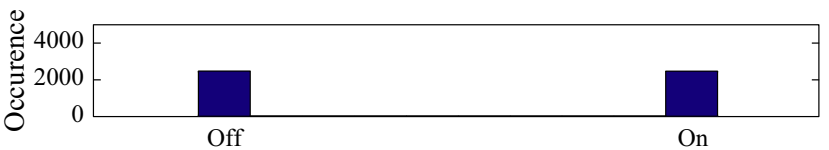

On/Off State

(d) Stage "+"

Fig. 5. The distributions of indoor temperatures of houses and of the on/off states of the thermostatic controllers of the DSRs.

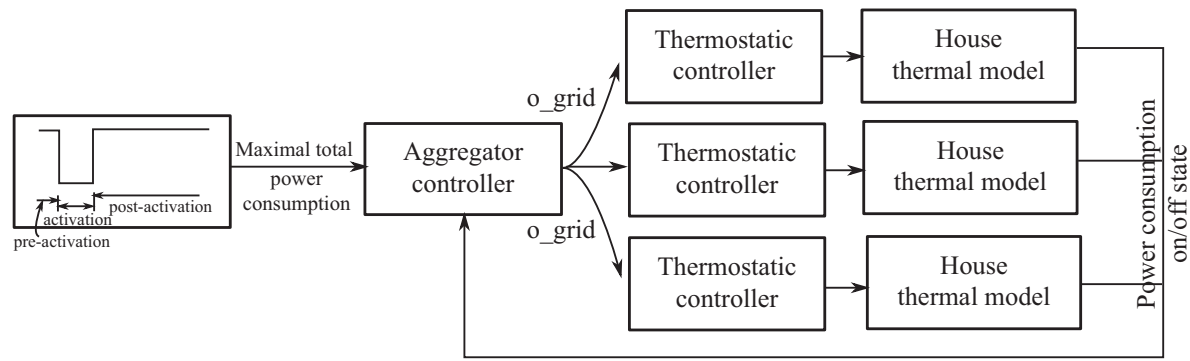

Aggregated power, individual on/off states

Fig. 6. Flow chart of the control strategy implemented between the aggregator and DSRs. 
power profile. Its knowledge of DSRs does not contain the internal state variables of the thermostatic controller, but only the on/off state and the aggregated power consumption.

In our work, a peak shaving DR program is utilized. The service requires that the total power consumption of all the loads should not exceed a maximal value (see Fig. 7). Activation period is estimated given the inelastic load profile as a baseline as shown in Fig. 7 with the arrows in a simulation with 5000 HPs. The maximal peak load is $13.6 \mathrm{MW}$, and the time when the load go above the maximal loading threshold value $12 \mathrm{MW}$ lasts $13 \mathrm{~h} 55$ min within the simulated 3 days.

The aggregator directly determines the state of the demand response setpoint $o_{\text {grid }}$ of individual DSRs based on the size of consumption to be curtailed. The number of $o_{\text {grid }}$ to be set to "off" is determined as follows.

$n_{o_{\text {grid }}=\text { off }}=\frac{P_{\text {curtail }}}{P_{\mathrm{HP}}^{\text {rate }} \cdot p_{\mathrm{HP}}^{\text {on }}}$

$p_{\mathrm{HP}}^{\text {on }}(t)= \begin{cases}p_{\mathrm{HP}, \text { steady }}^{\mathrm{on}} & \text { service activated at } t \\ p_{\mathrm{HP}}^{\mathrm{on}}(t-1)\left(1-\frac{n_{o_{\text {grid }}(t-1)}}{n_{\mathrm{HP}}}\right) & \text { otherwise }\end{cases}$

where $P_{\text {curtail }}$ is the difference between the peak consumption and the maximal loading threshold value, $p_{\mathrm{HP}}^{\text {on }}$ is the estimated probability of the DSRs that are in "on" state (i.e., consuming power).

\subsection{Impacts on grid operation}

Fig. 9 shows the total power consumption applying peaking shaving when the kick-back is not considered in the DR program. In this case, the aggregator controller does not need feedbacks from DSRs, and therefore, the control is conducted in a open loop.

The results show that after the activation period, a lot of HPs start to consume power at the same time. Similar oscillations in Fig. 1 are also observed. Some DSRs reach their saturation conditions (i.e., no flexibility is available) at the end of the curtailment, which leads to less activated DSRs. It is confirmed by Fig. 8, in which the total number of "on" state DSRs are plotted along time. The size of the new peak is approx. $15 \mathrm{MW}$, which is even higher than the original peak. The dynamic oscillations continue to create peaks after the first major kick-back peak. It is because that the aggregator does not successfully deliver the peak shaving service, the life time of the power system components, such as underground cables and overhead lines, may be shortened due to the new congestions, and the component may even be damaged because of that $[21,22]$.

\section{Solutions to kick-back effect mitigation}

Mitigating the kick-back effect is not equivalent to remove it. It is because that the kick-back effect happens along with the

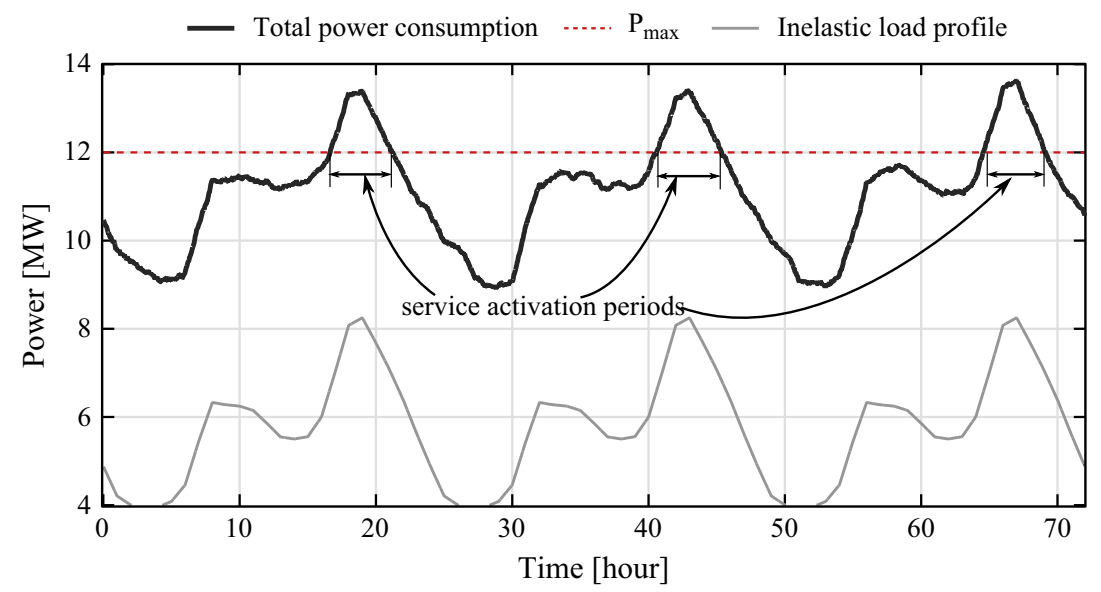

Fig. 7. Power consumption of 5000 thermostatically controlled heat pumps without DR program is added onto the system.

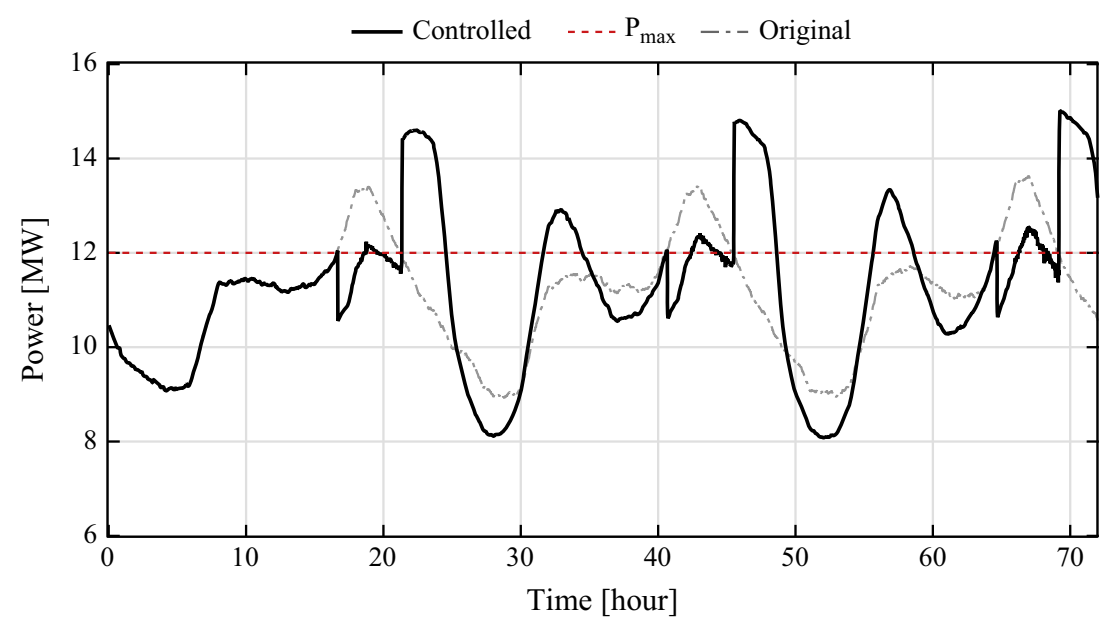

Fig. 8. Aggregated load profile of 5000 thermostatically controlled heat pumps during load kick-back effect in a peak shaving DR program. 
dynamic restoration process of DSRs back to their normal operating conditions. However, the shape of the kick-back load can be controlled to a certain extent (i.e., when all the DSRs reach their saturation operating conditions, there is no flexibility to shape the kick-back). In the peak shaving application, the goal is to maintain the total power consumption below the maximal power rating. Three control setups are proposed in this work as follows.

\subsection{Online direct coordination}

In this control setup, the feedbacks from DSRs are sent to the aggregator controller. Diversified control signals are sent to individual DSRs using the feedback information as a control input. The aggregator controller activates the DSRs with largest size of flexibility. The size of flexibility of individual DSRs is captured by comparing the length of current "on" time and the length of "on" time in a complete non-interfered cycle in the history. The simulation result is shown in Fig. 10. The maximal total load is $12.4 \mathrm{MW}$.

\subsection{Incentive signal based control}

The aggregator provides an incentive signal related to the loading of the system and motivate DSRs to react to the control signal. The DSRs calculate threshold values indicating their willingness to respond according to their indoor temperature. In this setup, the aggregator send out identical control signals, but the DSRs respond differently. The algorithm on the aggregator side:

$c_{\mathrm{DR}}=w \cdot \frac{P_{\text {curtail }}}{P_{\mathrm{HP}}^{\text {rate }} \cdot p_{\mathrm{HP}}^{\text {on }}}$ where $w$ is a weighting factor that need to be configured during the test of the control algorithm. Its value affects how sensitive the DSRs reacts to the DR control signal.

An illustrative example of the algorithm on the DSR side is presented in Fig. 11. The droop curve refers to the expected economic payback by providing flexibility from the HP owners. It reflects the utility function of individuals. The aggregator will incorporate these droop curves of individuals with primary technical constraints of components and the comfort need of customers. $c_{\text {thresload }}$ determines the slope of the droop curve, and the expected economic payback safety boundaries. $T_{\min }$ and $T_{\max }$ reflect the comfort zone preference of a HP owner.

When the threshold value of a DSR unit $c_{\text {threshold } j}$ (black curve) calculated from the indoor temperature $T_{\text {indoor }}$ (blue dotted line) is less than the incentive control signal $c_{D R}$ (red dotted line), the demand response setpoint $o_{\text {grid } j}$ is set to off. The parameters of the curve are randomized among the DSR fleet. The simulation result is shown in Fig. 12. The maximal load is 12.5 MW. Comparing to the previous method, this method does not require feedback during the real operation, but only during the testing when configuring the parameters.

\subsection{Configuring the DSR controllers with random components}

It is also possible to configure the DSR controllers in advance by adding some random temperature tolerance $\delta T$ to the local controllers and relaxing the minimal indoor temperature allowed in houses. In addition, random delays $\delta t$ are also added to local controllers after the service activation. By doing so, the response of

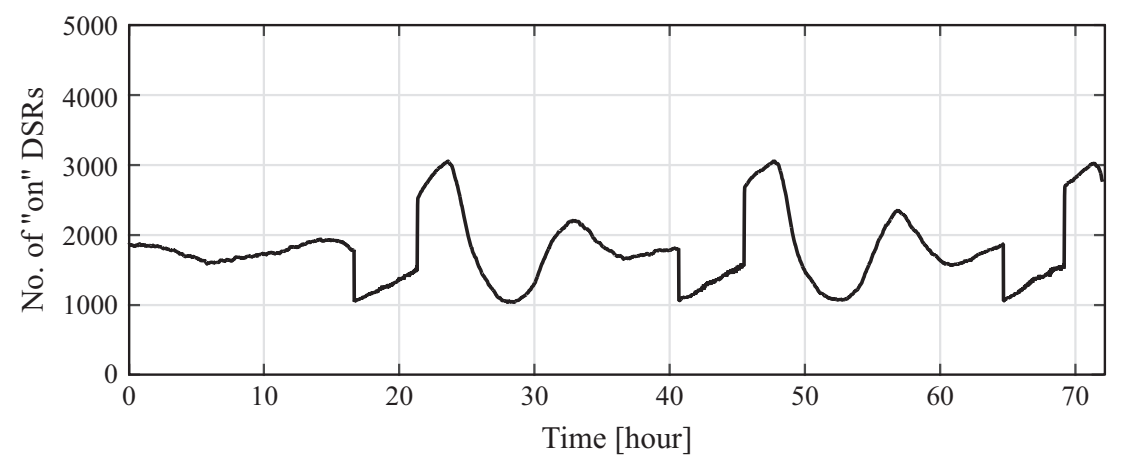

Fig. 9. The number of "on" state HPs along time.

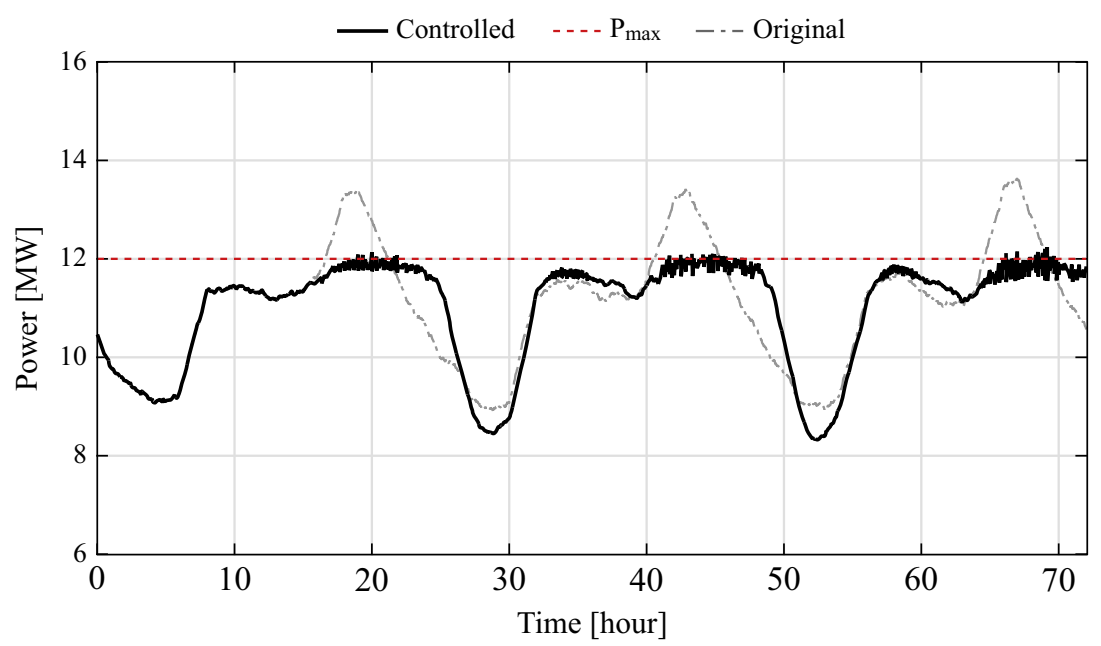

Fig. 10. Aggregated load profile of 5000 thermostatically controlled heat pumps in a peak shaving DR program with online direct control. 


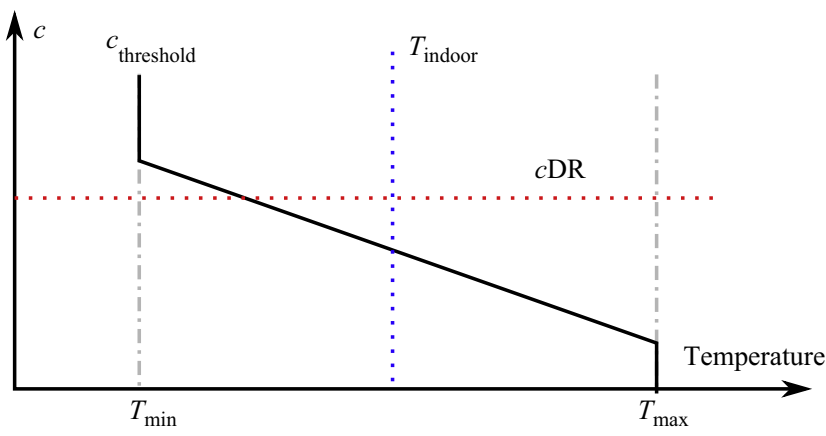

Fig. 11. The responding curve of a DSR unit. The slope and the reference point $\left(T_{\text {ref }}, c_{\text {ref }}\right)$ of the droop curve are randomized among the DSR fleet.

DSRs is diversified. Fig. 13 presents the simulation results of this control algorithm. It can be seen that adding the random components in the reference temperature range means the peak value is reduced by approx. $600 \mathrm{~kW}$. The damping of the oscillations is increased as well. However, the new peak is still exist and may endanger the system operation.

\section{Performance assessment and discussion}

Three quantitative performance metrics are used in this work to assess the performance of the services delivered to the power system operator.
- Response accuracy $(R)$ It is calculated by the energy [kWh] allocated above the maximal loading limit.

- New peak power $\left(P_{\text {peak }}\right)$ The most critical peak value $[\mathrm{kW}]$ along the simulation period.

- Cumulative failing period $(C)$ The overall time [min] when the total power consumption is above the maximal loading limit.

The results regarding these three metrics are summarized in Table 2. In addition to the simulations presented in the previous section, a more strict maximal power threshold $(11.5 \mathrm{MW})$ is implemented to compare the results.

The findings from the simulation results are listed as follows.

- Kick-back effect can significantly affect the performance of DR program. The values of all performance metrics of the cases with controllers that do not consider kick-back effects are much worse compared to the in the reference case.

- By implementing control algorithms that consider the kick-back effects in DR programs, the performance of controllers is much improved. It is shown that the values of all three metrics using direct control method and incentive signal based method are significantly reduced. The method introducing random components can only reduce the new peak created by kick-back effect.

- The saturation of DSRs affects the performance of the controller. By reducing the maximal loading value from $12 \mathrm{MW}$ to 11.5 MW, the aggregator needs to activate more energy to be shifted. However, the DSRs in the current setup cannot provide

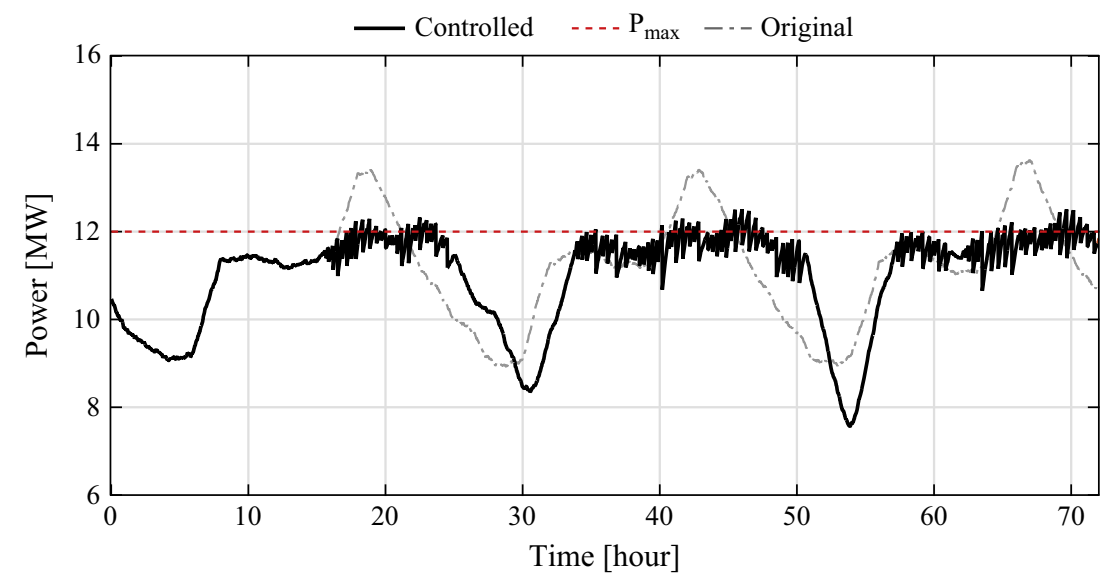

Fig. 12. Aggregated load profile of 5000 thermostatically controlled heat pumps in a peak shaving DR program with incentive signal based control.

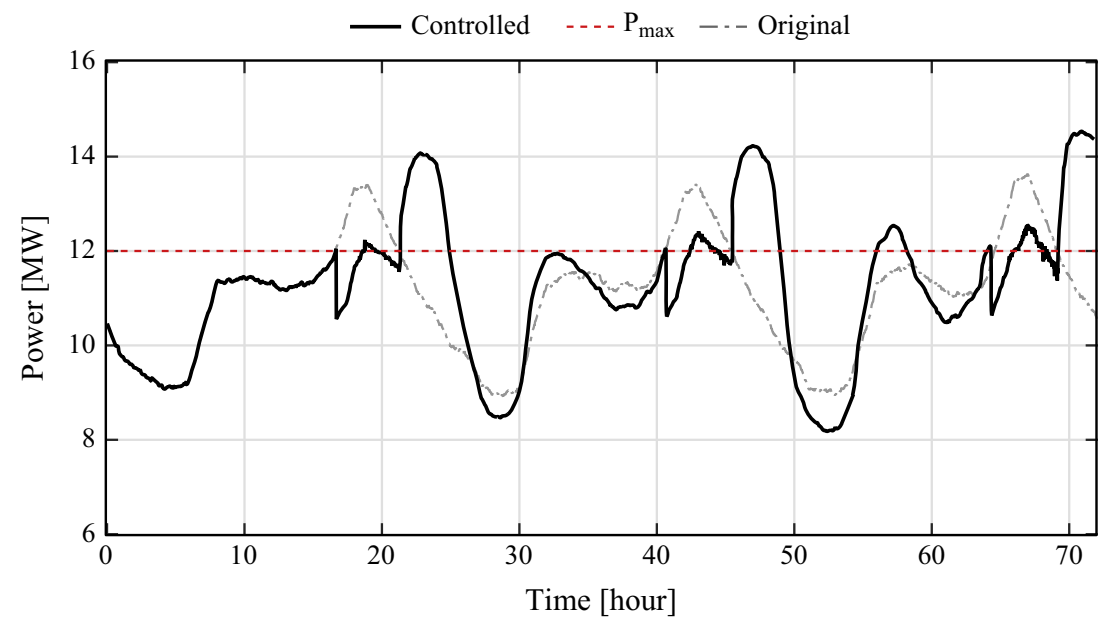

Fig. 13. Aggregated load profile of 5000 thermostatically controlled heat pumps in a peak shaving DR program with random components in local controllers. 
Table 2

Summary of the performance of different simulation cases.

\begin{tabular}{lcccc}
\hline & $P_{\max }[\mathrm{MW}]$ & $R[\mathrm{kWh}]$ & $P_{\text {peak }}[\mathrm{MW}]$ & $C[\mathrm{~min}]$ \\
\hline Not controlled & - & 11,790 & 13.6 & 835 \\
Kick-back effect & 12 & 26,580 & 15 & 1267 \\
Direct & 12 & 554 & 12.4 & 303 \\
Incentive & 12 & 895 & 12.5 & 375 \\
Random & 12 & 12,974 & 14.4 & 576 \\
Kick-back effect & 11.5 & 8683 & 13.2 & 1308 \\
Direct & 11.5 & 3579 & 12.4 & 913 \\
Incentive & 11.5 & 4868 & 12.2 & 1003 \\
Random & 11.5 & 9017 & 13.4 & 1293 \\
\hline
\end{tabular}

Table 3

Summary of the implementation requirements.

\begin{tabular}{lccc}
\hline Requirements & Direct & Incentive & Random \\
\hline Control signal & Unique & Identical & Identical \\
Communication & Two way & Two way & Single way \\
Historical information & Need & No need & No need \\
System knowledge & No need & Need & No need \\
\hline
\end{tabular}

sufficient amount of flexibility to support. Therefore, it is reflected in the results that the values of the first and last performance metrics are increased, and the peak value maintain almost the same as when the maximal loading value is $12 \mathrm{MW}$. Therefore, it is important for the aggregator to estimate the capability of its belonging aggregated DSRs, so that the agreed service quality can be met.

In addition to the performance metrics listed above, the implementation concerns are also important to the aggregators to pick the algorithms. The implementation requirements for the proposed algorithms are summarized in Table 3. By correlating Tables 3 and 2, it can be seen that a control solution with better overall control performance needs higher impementation requirements.

\section{Conclusion}

The load kick-back effect is identified in some DR cases when a grid service is activated using the flexibility from DSRs. The underlying reason forming the kick-back load is described in this article with illustrative examples. Kick-back effects are created because of the synchronous actions of DSRs after the service activation period. New peaks are created consequently. The size of new peaks can reach the maximal power consumption of the population, when all the DSRs are saturated. Aggregators may fail to deliver the service with agreed quality, and the power system operator may experience difficulties on the operation because of the new peaks.

Three methods are introduced in this paper to handle critical kick-back issues in real time, namely direct coordination, incentive control, and randomization. Simulation results using all these three methods show that critical kick-back peak can be mitigated by them to some extent. But the exhaustion of flexibility belonging to the DSR fleet will affect the performance of any kinds. The comparison among these three methods are conducted in terms of their control performance and the implementation requirements. The size of new peaks can be significantly reduced by direct coordination and incentive control, whereas these methods requires more advanced communication enabling infrastructure. The simulations also show that the peak can be smoothed only when flexibility is still available during the post-activation period.

In this paper, the models of electric space heating systems are simplified. In order to obtain more realistic results, better models are essential, so that the impacts of ambient temperature, human activities and their interconnections can be considered in the simulations. In addition, a heat buffer plays an important role in a heating system, which is not very well considered in this work. A validated model of hot water tank will be added into our model to perform DR.

There are multiple types of electric heating and cooling systems, but they are with different technical constraints. To obtain an integrated DR program in a large area, all these types of systems could be combined to serve better the purpose. The future work also includes this aspect.

In the end, the practical issues will also be considered in the future work, such as evaluating the value of DR services. The cost of establishing the DR infrastructure, the cost of activating the DR services and the cost of losing the life-time of electric components and receiving power quality punishment should all be taken into consideration.

\section{References}

[1] Global wind report annual market update 2014, Tech. rep., Global Wind Energy Council, 2015.

[2] S. You, H. Segerberg, Integration of $100 \%$ micro-distributed energy resources in the low voltage distribution network: a Danish case study, Appl. Therm. Eng. 71 (2) (2014) 797-808.

[3] Buildings-to-Grid Technical Opportunities: Vision and Introduction, Tech. rep., United States Department of Energy, Mar. 2014. <http://energy.gov/eere/ buildings/>.

[4] K. Van Horn, G. Gross, Demand response resources are not all they're made out to be: the payback effects severely reduce the reported DRR economic and emission benefits, Electr. J. 26 (7) (2013) 86-97.

[5] P. Siano, Demand response and smart grids - a survey, Renew. Sustain. Energy Rev. 30 (2014) 461-478.

[6] S. Koch, Demand response methods for ancillary services and renewable energy integration in electric power systems (Ph.D. thesis), Power Systems Laboratory, ETH Zurich, 2012.

[7] N. O'Connell, P. Pinson, H. Madsen, M. O'Malley, Economic dispatch of demand response balancing through asymmetric block offers, IEEE Trans. Power Syst. 31 (4) (2016) 2999-3007.

[8] D.S. Callaway, I.A. Hiskens, Achieving controllability of electric loads, Proc. IEEE 99 (1) (2011) 184-199.

[9] D. Patteeuw, K. Bruninx, A. Arteconi, E. Delarue, W. Dhaeseleer, L. Helsen, Integrated modeling of active demand response with electric heating systems coupled to thermal energy storage systems, Appl. Energy 151 (2015) 306-319.

[10] Y. Li, B.L. Ng, M. Trayer, L. Liu, Automated residential demand response: algorithmic implications of pricing models, IEEE Trans. Smart Grid 3 (4) (2012) 1712-1721.

[11] S. Lee, C. Wilkins, A practical approach to appliance load control analysis: a water heater case study, IEEE Trans. Power Syst. PER-3 (4) (1983) 1007-1013.

[12] O. Sundstrom, C. Binding, Planning electric-drive vehicle charging under constrained grid conditions, in: 2010 International Conference on Power System Technology (POWERCON), IEEE, 2010, pp. 1-6.

[13] T. Ericson, Direct load control of residential water heaters, Energy Policy 37 (9) (2009) 3502-3512.

[14] F. Sehar, M. Pipattanasomporn, S. Rahman, A peak-load reduction computing tool sensitive to commercial building environmental preferences, Appl. Energy 161 (2016) 279-289.

[15] J. Hu, S. You, M. Lind, J. Østergaard, Coordinated charging of electric vehicles for congestion prevention in the distribution grid, IEEE Trans. Smart Grid 5 (2) (2014) 703-711.

[16] H. Zhao, Q. Wu, Q. Guo, H. Sun, Y. Xue, Distributed model predictive control of a wind farm for optimal active power control - part i: clustering-based wind turbine model linearization, IEEE Trans. Sustain. Energy 6 (3) (2015) 831-839.

[17] SYSLAB - a research facility for intelligent, active, and distributed power systems, <http://www.powerlab.dk/facilities/syslab.aspx>.

[18] Bygnings-og boligregistret, <www.bbr.dk>.

[19] F. Sossan, X. Han, H. Bindner, Dynamic behaviour of a population of controlledby-price demand side resources, in: 2014 IEEE PES General MeetingConference \& Exposition, IEEE, 2014, pp. 1-5.

[20] R. Green, The effect of cycling on heat pump performance, Tech. rep., EA Technology, Department of Energy and Climate Change, UK, 2012.

[21] H. Goh, N. Chin, Q. Chua, S. Lee, K. Goh, K. Teo, Critical aging segments of power transmission line, Am. J. Eng. Appl. Sci. 6 (4) (2013) 340-351.

[22] H. Tecer, E. Acer, H. Erol, M.C. Gunduz, Effect of aging on conductivity of heat resistant overhead line conductors, Mater. Sci. Forum 765 (2013) 783-787. 